validate an MRI based algorithm to reliably quantify the iron levels in the periphery of the hematoma.

Methods Institutional IRB was obtained for the study. We secured NIH funding to undertake the study in September 2018. We recruited 10 patients based on inclusion and exclusion criteria established for the study. The study protocol was to obtain MRI at day 3,14 and 30 following ICH. The MRI scans were performed without contrast. The sequences performed were T1, T2 and PADRE plus a multi-echo susceptibility weighted sequence. Relaxivity $(1 / \mathrm{T} 2 *-\mathrm{R} 2 *)$ maps were then created utilizing the multi-echo sequence in Matlab. Two consecutive volumes of interest (VOI) $1 \& 2$ rings were then manually drawn on the maps around the periphery of the hematoma, on all the axial slices demonstrating the hematoma, on all available date points in each individual patient. Identical contralateral brain VOI (Normal Control - NC) was also drawn at each corresponding MRI axial image slice. The average measurement values were then tabulated at pre-specified time points over a period of one month following the ICH. The R2* value was then extrapolated to an iron concentration (IC) measured from an iron phantom MRI with identical sequences.

Results 10 eligible patients with $\mathrm{ICH}$ and two controls were recruited to the study. The Mean R2* value Day 3: VOI 1; 53.59 (SD: 6.01) - IC 0.16 SD 0.02, VOI 2: 28.35 (SD: 5.17) - IC 0.08 SD 0.02, NC: 19.47 (SD: 2.85) - IC 0.05 SD 0.01. Day 14: VOI 1; 47.97 (SD: 5.43) - IC 0.14 SD 0.02, VOI 2: 27.19 (SD: 2.19) - IC 0.08 SD 0.01, NC: 18.94 (SD: 1.62) - IC 0.05 SD 0.01. Day 30: VOI 1; 49.14 (SD: 6.44) IC 0.15 SD 0.02 , VOI 2: 30.10 (SD: 3.41) - IC 0.09 SD 0.01 , NC: 19.93 (SD: 2.82) - IC 0.05 SD 0.01 .

Conclusion Our study, the first translational study of its kind, shows relatively reliable iron concentration measurements by MRI at the periphery of the hematoma over a period of 1 month following the $\mathrm{ICH}$, showing good correlation with previous animal study data over a similar duration. Larger study is needed with extended 180 day follow up to further validate the measurement algorithm with a view to potentially becoming an MRI based risk stratification strategy in $\mathrm{ICH}$ patients. In addition, the algorithm may be utilized for monitoring iron chelate therapy in ICH.

Disclosures N. Chaudhary: None. A. Pandey: None. J. Griauzde: None. J. Gemmete: None. R. Keep: None. G. Xi: None.

\section{0-030 OPTHALMIC ARTERY CHEMOTHERAPY IN RETINOBLASTOMA}

T Shokuhfar, R Abdalla*, S Ansari, M Hurley, B Rahmani, A Shaibani. Radiology, Northwestern University, Chicago, IL

\subsection{6/neurintsurg-2019-SNIS.30}

Purpose To evaluate the safety and efficacy of intra-arterial chemotherapy (IAC) for the treatment of children with retinoblastoma.

Methods and materials Retrospective chart review of all pediatric patients with retinoblastoma treated with intra-arterial chemotherapy was performed. Common femoral artery was accessed with the placement of $4 \mathrm{Fr}$ sheath in all procedures using ultrasound guidance. Marathon microcatheter was used with .008 or .010 inch wire. Initial angiography of the internal carotid artery was performed to evaluate the territories supplied by the ophthalmic artery and to exclude variant anatomy.
Results Sixty-six ophthalmic arteries in 16 patients (M:F=7:9; mean age $=21( \pm 9.2)$ months $)$ were catheterized for IAC. The median time for each procedure was under 30 minutes. Three patients had unilateral and 13 had bilateral retinoblastoma. forty-four infusions were performed through the right and 22 through the left side ophthalmic artery. The median number of IAC cycles per patient was 4.1. The Technical success rate was $98 \%$ (65 out of 66 procedures) excluding one patient due to the complex anatomy. Hypersensitivity reaction to Melphalan was seen in 2 patients (one requiring adrenaline) during the catheterization procedure. One child eventually ended in enucleation after 4 cycles of IAC.

Conclusions Intra-arterial chemotherapy is an acceptable treatment option for retinoblastoma with a considerable high success rate and low rate of complications; however, attention must be paid to the technical nuances of and indications for its use in order to avoid potential complications.

Disclosures T. Shokuhfar: None. R. Abdalla: None. S. Ansari: None. M. Hurley: None. B. Rahmani: None. A. Shaibani: None.

\section{0-031 ROLE OF RESISTIVITY INDEX ANALYSIS IN THE PREDICTION OF HEMODYNAMICALLY SIGNIFICANT VENOUS SINUS STENOSIS IN PATIENTS WITH IDIOPATHIC INTRACRANIAL HYPERTENSION}

${ }^{1} \mathrm{M}$ Mohammaden*, ${ }^{2} \mathrm{M}$ Rizwan Husain, ${ }^{1} \mathrm{D}$ Brunozzi, ${ }^{1} \mathrm{G}$ Atwal, ${ }^{1} \mathrm{~F}$ Charbel, ${ }^{1} \mathrm{~A}$ Alaraj. ${ }^{1}$ Neurosurgery, University of Illinois at Chicago, Chicago, IL; ${ }^{2}$ Neurology, University of Illinois at Chicago, Chicago, IL

10.1136/neurintsurg-2019-SNIS.31

Background The resistivity index (RI) in cerebral venous sinus stenosis (VSS) has not been studied in patients with idiopathic intracranial hypertension (IIH).

Objective To evaluate the role of resistivity index (RI) measured by quantitative MRV (QMRV) as a non-invasive tool in the diagnosis of venous hypertension associated with VSS in idiopathic intracranial hypertension (IIH).

Abstract 0-031 Table 1 Demographic data and RI between patient and control

\begin{tabular}{|c|c|c|c|}
\hline & Patients $n=13$ & Control $n=13$ & $P$ value \\
\hline \multicolumn{4}{|l|}{ Patients' demographics } \\
\hline Age (years) & $46.6 \pm 15.1$ & $39.9 \pm 19.4$ & 0.34 \\
\hline Gender (female) n (\%) & $10(76.9 \%)$ & $9(69.2 \%)$ & 0.13 \\
\hline Body mass index (BMI) & $28.9 \pm 8.5$ & $25.9 \pm 7.5$ & 0.35 \\
\hline $\begin{array}{l}\text { Lumbar puncture } \\
\text { opening } \\
\text { pressure (mmHg) }\end{array}$ & $37.2 \pm 6.6$ & 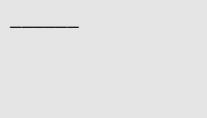 & \\
\hline $\begin{array}{l}\text { Unilateral VSS n (\%) } \\
\text { Resistivity index (RI) }\end{array}$ & $11(84.6 \%)$ & $\longrightarrow$ & 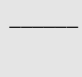 \\
\hline Superior sagittal sinus & $\begin{array}{l}0.21 \pm 0.12 \\
(95 \% \mathrm{Cl} 0.14-0.28)\end{array}$ & $\begin{array}{l}0.11 \pm 0.06 \\
(95 \% \mathrm{Cl} 0.08-0.15)\end{array}$ & 0.01 \\
\hline Transverse sinus & $\begin{array}{l}0.22 \pm 0.12 \\
(95 \% \mathrm{Cl} 0.15-0.30)\end{array}$ & $\begin{array}{l}0.13 \pm 0.07 \\
(95 \% \mathrm{Cl} 0.09-0.17)\end{array}$ & 0.03 \\
\hline Sigmoid sinus & $\begin{array}{l}0.15 \pm 0.06 \\
(95 \% \mathrm{Cl} 0.12-0.19)\end{array}$ & $\begin{array}{l}0.11 \pm 0.06 \\
(95 \% \mathrm{Cl} 0.07-0.14)\end{array}$ & 0.07 \\
\hline
\end{tabular}

All values are presented as (mean \pm SD) unless indicated otherwise. Boldface type indicates statistical significance. VSS; venous sinus stenosis, $\mathrm{Cl}$; confidence interval 
Abstract 0-031 Table 2 MVP and RI in patients (pre and poststenting)

\begin{tabular}{lcll}
\hline & Pre stenting $\mathrm{n}=11$ & Post stenting $\mathrm{n}=11$ & P value \\
\hline Mean venous sinus pressure & (MVP) $\mathbf{m m H g}$ & & \\
Superior sagittal sinus & $41.9 \pm 14.6$ & $22.5 \pm 8.4$ & $<0.001$ \\
Transverse sinus & $39.4 \pm 15.1$ & $19.5 \pm 8.2$ & $<0.001$ \\
Sigmoid sinus & $16.3 \pm 6.2$ & $17.5 \pm 6.7$ & 0.23 \\
Pressure difference across the & $22.8 \pm 13.3$ & $1.8 \pm 1.1$ & $<0.001$ \\
stenosis & & & \\
Resistivity index (RI) & & & \\
Superior sagittal sinus & $0.22 \pm 0.13$ & $0.17 \pm 0.11$ & $<0.01$ \\
Transverse sinus & $0.23 \pm 0.13$ & $0.17 \pm 0.08$ & 0.03 \\
Sigmoid sinus & $0.16 \pm 0.05$ & $0.16 \pm 0.11$ & 0.84 \\
\hline
\end{tabular}

All values are presented as (mean \pm SD). Boldface type indicates statistical significance

Abstract 0-031 Table 3 RI changes across stenosis (pre and post-stenting)

\begin{tabular}{llll}
\hline & $\begin{array}{l}\text { Resistive index } \\
\text { Proximal to stenosis }\end{array}$ & Resistive index distal to stenosis & P value \\
\hline Pre-stenting & $0.24 \pm 0.12$ & $0.15 \pm 0.06$ & 0.03 \\
Post-stenting & $0.17 \pm 0.09$ & $0.15 \pm 0.1$ & 0.66 \\
\hline
\end{tabular}

All values are presented as (mean $\pm \mathrm{SD}$ ). Boldface type indicates statistical significance

Methods Retrospective evaluation of 13 consecutive $\mathrm{IIH}$ patients who underwent venous sinus stenting at our institution between 2013-2018 was reviewed.

Patients' demographics, clinical presentation, cerebral mean venous sinus pressure (MVP) and RI both pre and post-stenting were recorded. The baseline RI was also compared to a control group.

Results Among 13 patients of IIH, 11 had unilateral VSS in dominant sinus, while 2 had bilateral VSS. RI was significantly higher in IIH patients compared to the control group in the superior sagittal (SSS) and transverse sinuses (TS) (0.21 vs $0.11, \mathrm{p}=0.01$ and 0.22 vs $0.13, \mathrm{p}=0.03$, respectively). The MVP (in $\mathrm{mmHg}$ ) decreased significantly after venous sinus stenting in the SSS $(41.9$ to $22.5, \mathrm{p}<0.001)$ and TS (39.4 to $19.5, \mathrm{p}<0.001)$ which was also associated with a significant reduction of the RI $(0.22$ vs. $0.17, \mathrm{p}<0.01$ in SSS and 0.23 vs. $0.17, p=0.03$ in TS) post-stenting.
Conclusion RI calculated using QMRV can serve as a noninvasive tool to aid in the diagnosis of hemodynamically significant VSS. The study had a small sample size, and larger multicenter studies would be required to validate the results further.

Disclosures M. Mohammaden: None. M. Rizwan Husain: None. D. Brunozzi: None. G. Atwal: None. F. Charbel: None. A. Alaraj: 1; C; NIH. 2; C; Cerenovus.

\section{0-032 MICROCATHETER DELIVERY OF NEUROTHERAPEUTICS: COMPATIBILITY WITH MESENCHYMAL STEM CELLS}

${ }^{1} \mathrm{~V}$ Srinivasan*, ${ }^{1} \mathrm{~J}$ Gumin, ${ }^{1} \mathrm{~K}$ Camstra, ${ }^{2} \mathrm{~S}$ Chen, ${ }^{1} \mathrm{~J}$ Johnson, ${ }^{1} \mathrm{~F}$ Lang, ${ }^{1} \mathrm{P}$ Kan. ${ }^{1}$ Neurosurgery, Baylor College of Medicine, Houston, TX; ${ }^{2}$ Radiology, Baylor College of Medicine, Houston, TX

\subsection{6/neurintsurg-2019-SNIS.32}

Background Mesenchymal stem cells (MSCs) are being studied for the treatment of several neurological disorders. The use of MSCs as delivery modality for targeted viral therapeutic agents for the treatment of intracranial pathologies has not been explored. Delta-24-RGD, a tumor-selective oncolytic adenovirus designed to target malignant glioma cells, has been shown effective in animal models. However, the most efficient viral tissue delivery modality is unclear. Bone marrow human MSCs (BM-hMSC) have been shown to have homing capability toward glioma xenografts and the feasibility of oncolytic virus particles loaded in MSCs being delivered to the tumor vascular bed via selective intra-arterial (IA) infusion is being investigated. To evaluate the feasibility of endovascular IA delivery, catheter compatibility with MSCs was tested in vitro. Methods BM-hMSCs were cultured, transfected with Delta-24, and re-suspended in 1\% Human Serum Albumin. hMSCDelta-24 solution was then injected via three microcatheters of different inner diameters (Marathon, Echelon-14, and Marksman). Cell count and viability after injection through the microcatheters based on injection velocity and catheter configuration were assessed. Transwell assay was performed with the injected cells to test the Delta-24 activity against U87 glioma cells. hMSC-Delta-24 compatibility was also tested with commonly used medications in neuroendovascular therapy (Omnipaque, verapamil, and heparin).

Results BM-hMSC cell count prior to infusion was $0.123 \times$ $10^{6}$ cells $/ \mathrm{mL}, 98.7 \%$ viability. There was no significant difference in cell count after infused through any of the catheters

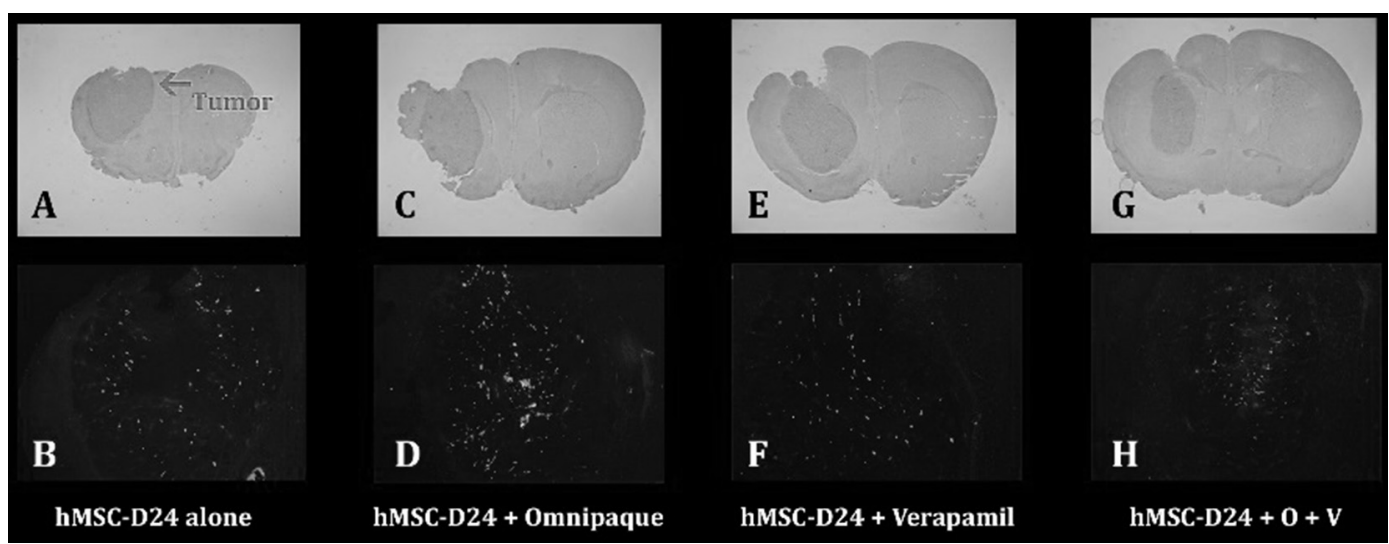

Abstract 0-032 Figure 1 H\&E slides (top row, A, C, E, G) and corresponding GFP-stained sections (bottom row, B, D, F, H) of nude mouse cerebri. The magnified GFP sections show diffuse localization of the GFP-labeled Delta-24-hMSCs throughout the tumor following IA injection 